\section{Snare-over-scope technique for retrieval of a proximally migrated biliary stent}
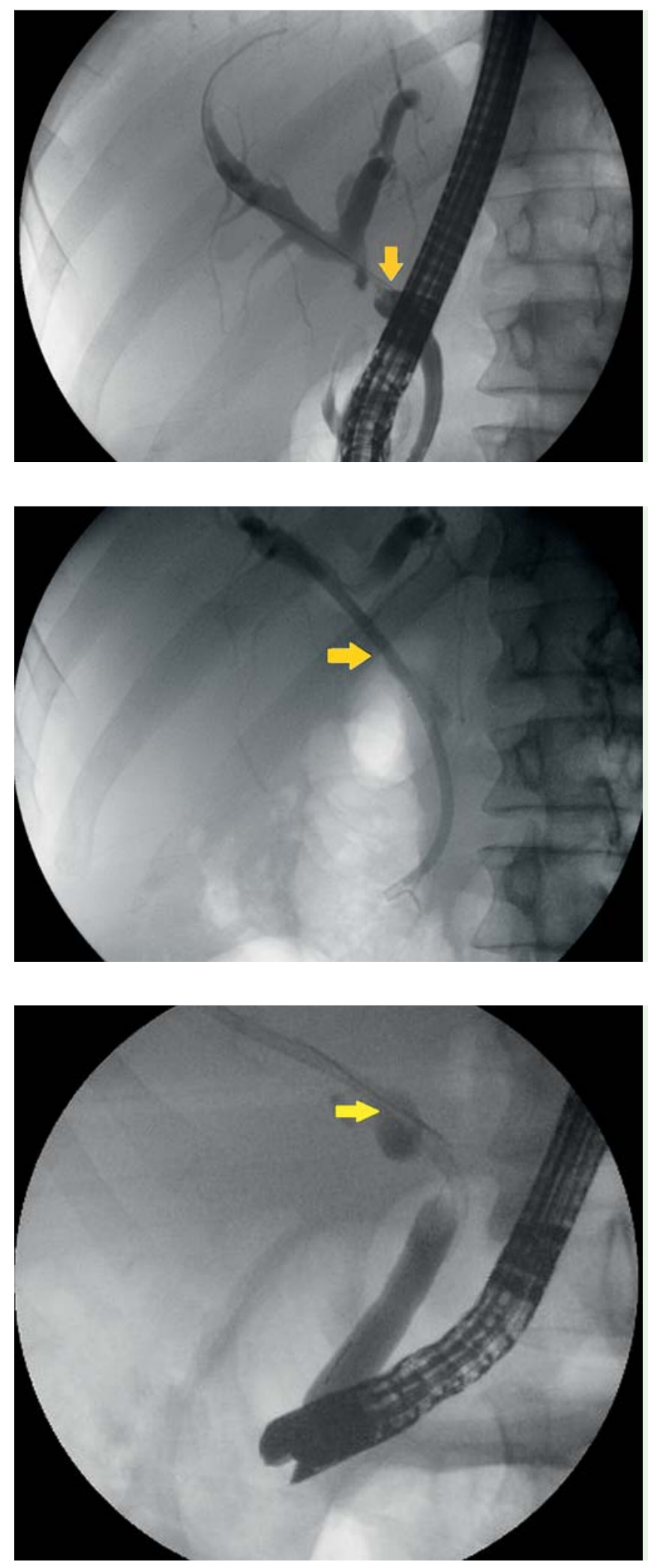

Fig. 1 Cholangiogram demonstrating a 5-mm biliary stricture in the common hepatic duct (arrow).

Fig. 2 Biliary stent deployed in the optimal position across the stricture (arrow).

Fig. 3 Cholangiogram demonstrating biliary sphincteroplasty. The proximally migrated $10 \mathrm{Fr} \times 9 \mathrm{~cm}$, plastic stent is seen entirely within the bile duct (arrow).
There is no consensus on the optimal technique for retrieval of proximally migrated biliary stents. A biliary sphincterotomy or sphincteroplasty, together with the use of accessories such as stentgrasping forceps, Soehendra stent retrieval device, and stone extraction balloon, have been reported [1-4]. We present the case of a proximally migrated biliary stent that was retrieved using a novel "snare-over-scope" (SOS) technique.

A 25-year-old woman underwent endoscopic retrograde cholangiopancreatography (ERCP), which revealed a 5-mm common hepatic duct stricture caused by extrinsic compression from a periportal lymph node ( $\bullet$ Fig. 1 ). Consequently, a $10 \mathrm{Fr} \times 9 \mathrm{~cm}$, straight, plastic stent was deployed across the stricture ( $\bullet$ Fig. 2 ).

The patient's clinical and biochemical parameters did not resolve, and repeat ERCP was performed revealing proximal migration of the stent ( Fig.3). Despite extension of the biliary sphincterotomy and sphincteroplasty to $12 \mathrm{~mm}$, and the use of stent-grasping forceps, the stent could not be retrieved. On several occasions, the stone extraction balloon was able to drag the stent out through the major papilla, but when the balloon was deflated to exchange it for a snare, the stent slipped back into the bile duct.

It was recognized that the stent had to be stabilized within the duodenum prior to grasping. A polypectomy snare was taped to the exterior of the duodenoscope, oriented along the biopsy channel and with the snare closed around the tip of the scope ( Fig.4, Video 1 ). The duodenoscope with snare was advanced as a single unit to the major papilla. The stent was brought out through the biliary orifice using the inflated stone extraction balloon, and the snare was opened and closed around the stent ( Fig.5). The balloon was deflated and the endoscope, together with the snare grasping the stent, was removed from the patient. A $10 \mathrm{Fr} \times 12 \mathrm{~cm}$, straight, plastic stent was then inserted across the stricture with ample length remaining in the duodenum.

\section{Video 1}

Demonstration of the equipment set-up and the stent being removed from the bile duct using the "snare-over-scope" technique. 


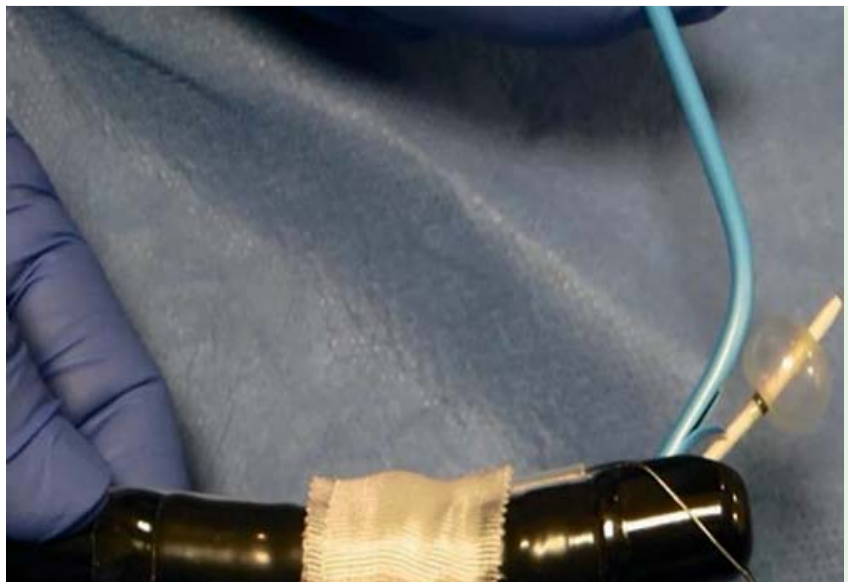

Fig.4 In vitro image demonstrating the polypectomy snare taped to the exterior of the duodenoscope along the biopsy channel, with the snare closed around the tip of the scope.
This case demonstrates the innovative SOS technique, which effectively creates a second over-the-scope port, allowing an accessory to be used to secure and retrieve a biliary stent. This technique could also be employed for stents that have migrated proximally into the pancreatic duct.

\section{Endoscopy_UCTN_Code_TTT_1AR_2AZ}

Competing interests: Dr. Khashab is a Consultant for Boston Scientific and Olympus America, and has received research support from Cook Medical. Dr. Saxena is a Consultant for Boston Scientific and has received research support from Cook Medical. Dr. Lennon is a consultant for Boston Scientific. Dr. Singh is a consultant for Abbvie, Santarus, D-Pharm, Enteromedics, Novo Nordisk, and Boston Scientific.

\section{Ahmed Abdelgelil, Vivek Kumbhari, Alan H. Tieu, Payal Saxena, Sepideh Besharati, Saowanee Ngamrueng- phong, Mohamed El-Zein, Gerard Aguila, Vikesh Singh, Anne Marie Lennon, Mouen A. Khashab}

Department of Medicine, Division of Gastroenterology and Hepatology, The Johns Hopkins Medical Institutions, Baltimore, Maryland, United States

\section{References}

1 Sakai Y, Tsuyuguchi T, Ishihara $T$ et al. Cholangiopancreatography troubleshooting: the usefulness of endoscopic retrieval of migrated biliary and pancreatic stents. Hepatobiliary Pancreat Dis Int 2009; 8: 632 -637

2 Katsinelos P, Kountouras J, Paroutoglou G et al. Migration of plastic biliary stents and endoscopic retrieval: an experience of three referral centers. Surg Laparosc Endosc Percutan Tech 2009; 19: 217-221

3 Vila JJ, Ruiz-Clavijo D, Fernández-Urién I et al. Endoscopic retrieval of a proximally migrat-

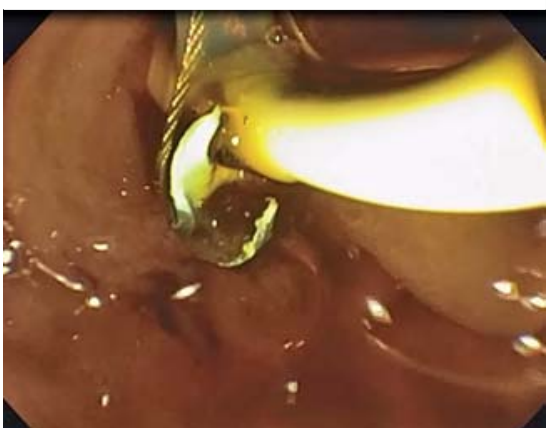

Fig. 5 Snare closed around the stent.

ed pancreatic stent: variation of the lasso technique. Endoscopy 2010; 42: E5 - E6

4 Nakai Y, Isayama H, Kawakubo Ket al. Endoscopic removal of a biliary covered metallic stent with the invagination method. Endoscopy $2011 ; 43$ : E30-31

\section{Bibliography}

Dol http://dx.doi.org/

10.1055/s-0034-1390847

Endoscopy 2014; 46: E650-E651

(c) Georg Thieme Verlag KG

Stuttgart · New York

ISSN 0013-726X

\section{Corresponding author}

Mouen A. Khashab, MD

Division of Gastroenterology and Hepatology

The Johns Hopkins Hospital

Sheikh Zayed Tower, Suite 7125B

1800 Orleans Street

Baltimore, MD 21287

United States

Fax: +1-443-683-8335

mkhasha1@jhmi.edu 